\title{
JUSTIÇA RESTAURATIVA COMO INSTRUMENTO DE EFETIVIDADE DA TUTELA JURISDICIONAL AO DEPENDENTE QUÍMICO
}

RESTORATIVE JUSTICE AS AN INSTRUMENT OF EFFECTIVENESS JUDICIAL
PROTECTION THE CHEMICAL DEPENDENT

Maria Edna de Jesus Dias

Mestranda em Prestação Jurisdicional e Direitos Humanos pela Universidade Federal do Tocantins (UFT), em parceria com a Escola Superior da Magistratura Tocantinense (ESMAT)

\section{RESUMO}

Os problemas sociais relacionados à violência como resultado do uso abusivo de drogas e sua consequente dependência química têm suscitado questionamentos em torno de decisões judiciais para resolução desses conflitos. Observa-se que a aplicação da Justiça Retributiva não tem surtido os resultados esperados na pacificação social. Assim, como forma de resguardar preceitos constitucionais da dignidade humana, surge a Justiça Restaurativa com a finalidade de não só punir o infrator, como também ajudá-lo em sua reinserção social e tratamento adequado e humano. Nessa justiça, a vítima é participante ativa, na comunidade, na resolução do conflito. Assim, este trabalho procurará demonstrar que a Justiça Restaurativa tem papel fundamental como instrumento de efetividade da tutela jurisdicional ao dependente químico.

PALAVRAS-CHAVE: Justiça restaurativa; Instrumento de efetividade; Tutela jurisdicional; Dependente químico.

\section{ABSTRACT}

Social problems related to violence as a result of drug abuse and its consequent addiction have raised questions around court decisions to resolve these conflicts. It is observed that the application of retributive justice has not had the expected results in social peace. Thus, in order to safeguard constitutional principles of human dignity, Restorative Justice arises, in order to not only punish the offender but also help you in your social reintegration and proper and humane treatment. This justice, the victim is an active participant, in the community, in resolving the conflict. This work will seek to 
demonstrate that restorative justice plays a key role as an instrument of effective judicial protection to drug addict.

KEYWORDS: Restorative Justice; Effective tool; Judicial protection; Addict.

\section{INTRODUÇÃO}

As situações de violência e conflitos presentes nos convívios sociais geram insatisfação quanto às respostas jurisdicionais atuais na área penal. Discute-se se as penalidades impostas aos infratores recuperam estes e se trazem benefícios à vítima, assim como para a sociedade de forma geral.

Nesse contexto, surge um sentimento de desconfiança no sistema judicial, pois se observa que o aparelho judiciário não evoluiu para resolver problemas contemporâneos relacionados à violência. Essa situação se agrava com o fato de o consumo de drogas ter se expandido de forma alarmante, sendo apontado como um dos fatores de aumento da criminalidade. Assim, o enfrentamento à violência deve ser conjunto ao enfrentamento do uso de drogas e dependência química.

$\bigcirc$ Direito Penal consiste em um conjunto de normas proibitivas que regulam a relação social dos indivíduos e tutelam os bens jurídicos fundamentais como ultima ratio. Se houver transgressão, o Estado impõe sanção ao infrator, a fim de retribuir-lhe o mal praticado contra a sociedade.

Constata-se que os bens violados interessam ao indivíduo e à coletividade, o que torna a relação entre o infrator e a vítima secundária, revelando o direito de persecutio criminis e o ius accusationis da vítima, mas não o ius puniendi, que detém apenas o Estado, daí o caráter público do Direito Penal. Mas, na evolução do Direito, há tendência de se diminuir o caráter retributivo da pena, único aplicável, a fim de dar vazão à recuperação do indivíduo infrator(BITENCOURT, 2004).

Para tentar resolver esses conflitos, trazer a paz social e garantir os direitos fundamentais da pessoa humana, surge a Justiça Restaurativa para contribuir com a já aplicada Justiça Tradicional ou Retributiva. O novo modo de se aplicarem as penalidades infligidas ao indivíduo busca superar as limitações do modo tradicional, pois se baseia no diálogo, na responsabilidade e na inclusão social; assim, vítima e comunidade têm papel fundamental na solução do conflito (PENIDO; MELO, 2005).

A complementaridade da Justiça Restaurativa à Justiça Retributiva se dá em respeito ao Estado Democrático de Direito, em que infrator, vítima e sociedade têm seus direitos garantidos. E sua finalidade consiste na efetividade e na pacificação das relações sociais, ao atualizar e promover a chamada democracia ativa. 
Dessa forma, o presente estudo pressupõe que a Justiça Restaurativa seja instrumento de efetividade da tutela jurisdicional também do dependente químico, muitas vezes sujeito ativo no ciclo de violência.

\section{AJUSTIÇARESTAURATIVA}

A doutrina cita duas formas de se aplicar a justiça criminal por meio do Estado, em seu exercício do jus puniendi: justiça retributiva ou restaurativa.

Conforme lições de Gomes Pinto (2005), os elementos básicos da Justiça Retributiva são: o crime é ato contra a sociedade, representada pelo Estado; o interesse na punição é público; a responsabilidade do agente é individual; há o uso estritamente dogmático do Direito Penal; utiliza-se de procedimentos formais e rígidos; predomina a indisponibilidade da ação penal; a concentração do foco punitivo volta-se ao infrator; há o predomínio de penas privativas de liberdade; existem penas cruéis e humilhantes; consagra-se a pouca assistência à vítima; a comunicação do infrator é feita somente pelo advogado.

De outro modo, os elementos da Justiça Restaurativa, de acordo com Nucci (20 I 5), são: o crime é ato contra a comunidade, contra a vítima e contra o próprio infrator; o interesse de punir e reparar pertence às pessoas envolvidas no caso; há responsabilidade social pelo ocorrido; predomina o uso alternativo e crítico do Direito Penal; existem procedimentos informais e flexíveis; predomina a disponibilidade da ação penal; há uma concentração de foco conciliador; existe o predomínio da reparação do dano causado ou da prestação de serviços comunitários; as penas são proporcionais e humanizadas; o foco de assistência é voltado à vítima; a comunicação do infrator pode ser feita diretamente ao Estado ou à vítima.

Sobre a Justiça Restaurativa, Santos (201 I , p. 30) expõe que

[...] podemos entender a Justiça Restaurativa com uma reformulação de nossa concepção de justiça, tendo como objetivos trabalhar a compreensão das pessoas sobre a situação conflituosa para que haja a humanização dos envolvidos, possibilitando a identificação das necessidades geradas pelo conflito/crime e a consequente responsabilização de todos os afetos, direta ou indiretamente, para que, de uma forma ou de outra, se comprometam e contribuam para sua resolução.

Observa-se, analisando as características das duas modalidades, que o sistema penal brasileiro contém elementos dos dois sistemas teóricos apresentados. Ainda há elementos de que o Estado não se vale mais, porque ultrapassados (NEVES, 20 I 0).

A Justiça Terapêutica - Restaurativa - procura auxiliar o cumprimento da legislação: a Lei de Execução Penal; as Leis que criaram os juizados especiais estaduais e federais; os Tratados de Direitos Humanos, de forma harmônica com a Constituição Federal. 
Constitui-se em programas com medidas sociais e de tratamento às pessoas que praticam crimes, nos quais o elemento droga esteja presente de alguma forma. Normalmente, o sistema penal brasileiro aplica a pena ao agente com a privação de sua liberdade. Esse novo modelo restaurador busca, além da punição, sobretudo, a proteção ao indivíduo em face de eventuais abusos do Estado.

Dessa forma, além de estabelecer uma norma restaurativa, a Lei n ${ }^{\circ}$.343, de 2006, Lei do Sistema Nacional de Políticas Públicas sobre Drogas (SISNAD), garante ao sujeito tanto a infração penal incumbida a ele, como também o tratamento médico, fundamentado no artigo $5^{0^{\prime}}$ da Constituição Federal.

$\bigcirc$ problema jurídico da violência se resolve com o sistema penal meramente acusatório, e não conciliador, mas não resolve o problema entre as partes de fato. Nesse modelo, chega-se a utilizar a vítima para os embates técnicos jurídicos, mas não há auxílio para ela. Também somente a aplicação da pena não é suficiente para a diminuição da criminalidade e o aumento da segurança pública. Isso porque o infrator cumpre sua pena, mas não é ressocializado, e reincide, enquanto que a vítima não é assistida em suas necessidades (SANTOS, 20 I I).

Tem-se, assim, a Justiça Restaurativa como um processo em que todas as partes interessadas em um delito específico empenham-se em solucioná-lo e decidem como lidar com seu resultado e suas implicações no futuro. Em outras palavras, tem-se que o diálogo deve ocorrer entre a vítima, o infrator e a comunidade na qual estão inseridos. Dessa forma, devem-se "identificar as necessidades e obrigações oriundas dessa violação e do trauma causado e que deve ser restaurado" (PINTO, 2005, p. 2 I ).

Sabe-se que ao Estado é incumbida a tarefa de solucionar o conflito e as suas consequências. No entanto, na Justiça Restaurativa, o Estado cede alguma autoridade para representantes da sociedade civil, pois estes teriam mais condições de serem intermediadores do problema. Isso porque o ambiente pode ser mais acolhedor às partes, o que nem sempre ocorre quando se está na presença de representantes da Justiça (OXHORN; SLAKMON, 2005).

Salienta-se que, quando há a aplicação da Justiça Restaurativa, tenta-se resolver a ação penal antes de se desenvolver como lide judicial. Isso decorre dos princípios da celeridade e da economia processual, pois o litígio é solucionado como um todo: a vítima pode ser reparada e expor as consequências da infração; o infrator pode responder pelo ilícito de forma digna e humana (SANTOS, 201 I).

\footnotetext{
Art. $5^{\circ}$ Todos são iguais perante a lei, sem distinção de qualquer natureza, garantindo-se aos brasileiros e aos estrangeiros residentes no País a inviolabilidade do direito à vida, à liberdade, à igualdade, à segurança e à propriedade [...].
} 
A Justiça Restaurativa, ao contrário do pensamento de muitos que são contra esse modelo, não se propõe a que haja impunidade dos infratores. Observa-se isso quando o infrator é responsabilizado para que haja o ressarcimento da vítima e da comunidade, e busca-se a reinserção do infrator nesta. A reinserção ocorre após ter a chance de compreender os efeitos de sua conduta no círculo restaurativo.

No Brasil, os princípios que embasam esse modelo de justiça estão presentes na Carta de Araçatuba, de 30 de abril de 2005²; na Carta de Brasília, de 17 de junho de 2005; na Carta do Recife sobre Justiça Restaurativa, de 12 de abril de $2006^{4}$; e na Carta de São Luís sobre Justiça Juvenil Restaurativa, de 9 de julho de $2010^{5}$ (PENIDO, 2005).

Podem-se citar como princípios básicos os que se apresentam resumidos na Resolução do Conselho Econômico e Social das Nações Unidas, de 13 de agosto de 2002, quais sejam: programa restaurativo, processo restaurativo e resultado restaurativo. $O$ primeiro se refere a qualquer programa que utiliza processos restaurativos voltados para resultados restaurativos. $\bigcirc$ segundo, à participação coletiva e ativa da vítima e do infrator, e, quando apropriado, de outras pessoas ou membros da comunidade afetados pelo crime, na resolução dos problemas causados por este, geralmente com a ajuda de um facilitador, abrangendo mediação, conciliação, audiências e círculos de sentença. E o último, o acordo alcançado por um processo restaurativo, incluindo responsabilidades e programas, como reparação, restituição, prestação de serviços comunitários, a fim de suprir as necessidades individuais e coletivas das partes, logrando a reintegração da vítima e do infrator (BACELLAR; NETO, 20II).

${ }^{2}$ Carta de Araçatuba. Princípios de justiça restaurativa. Carta elaborada pelos integrantes do I Simpósio Brasileiro de Justiça Restaurativa. 28/30 de abril de 2005, na Cidade de Araçatuba/São Paulo. Disponível em: <http://jij.tjrs.jus.br/justica-restaurativa/carta-aracatuba >. Acesso em 7 jun. 2015.

${ }^{3}$ Carta de Brasília. Documento ratificado pelos painelistas e participantes da Conferência Internacional "Acesso à Justiça por Meios Alternativos de Resolução de Conflitos", realizada na cidade de Brasília, Distrito Federal, nos dias I4, I5, 16 e 17 de junho de 2005, com base na carta produzida, em abril do corrente ano, no I Simpósio Brasileiro de Justiça Restaurativa, realizado em Araçatuba-SP, em abril de 2005. Disponível em: <http://ow.ly/KNICZ>. Acesso em 9 jun. 2015. ${ }^{4}$ Carta de Recife. A Carta de Recife foi elaborada por integrantes e aprovada pelos participantes do Il Simpósio Brasileiro de Justiça Restaurativa, realizado na Cidade do Recife, Estado de Pernambuco - Brasil, nos dias 10, II e 12 de abril de 2006. Disponível em: $<$ http://www.justica21.org.br/j2I.php?id=225\&pg=0\#.VZHWlfViko >. Acesso em 9 jun. 2015.

${ }^{5}$ Carta de São Luís. Carta elaborada pelos integrantes do I Seminário Brasileiro de Justiça Juvenil Restaurativa, que aconteceu de 7 a 9 de julho de 2010, em São Luís, capital do estado do Maranhão. Disponível em: <http://portal.andes.org.br/imprensa/noticias/imp-ult732896191.pdf>. Acesso em 9 jun. 2015. 
Howard Zehr, na obra "Trocando as Lentes", afirma que a sociedade ocidental questiona: Que lei foi violada? Quem fez isso? O que ele merece? E propõe os seguintes questionamentos: Quem sofreu o dano? Quais são as suas necessidades? Quem tem obrigação de supri-las? Quais as causas? Quem tem interesse na situação? Qual o processo apropriado para envolver os interessados no esforço de tratar das causas e corrigir a situação? (AMANClO, 20 I I).

Essa é uma nova forma de alcançar a Justiça, pois o modelo de política criminal brasileiro está em desconformidade com a atualidade que se apresenta, ou seja, diante do ciclo de criminalidade, do uso de drogas e da impunidade. A Justiça Restaurativa surge para incentivar os envolvidos ao diálogo e ao acordo, procurando, assim, a cura do mal sofrido, de forma que a Justiça atuará para atribuir as responsabilidades pelo delito, mas com o encaminhamento ao tratamento terapêutico individual e coletivo, com vista à redução dos impactos do crime sobre as pessoas, resultado pretendido com essa espécie de Justiça (AMANCIO, 20I I).

Como pressupostos básicos para que seja possível aplicar a Justiça Restaurativa, a Organização das Nações Unidas publicou o Manual de Programas de Justiça Restaurativa (2006), citando que, para que a mediação vítima/agressor possa ter lugar, o agressor deve aceitar (ou não negar) sua responsabilidade pelo crime; vítima e agressor devem ser livres de participar, ou não, no processo; e vítima e agressor devem sentir segurança ao participar no processo de mediação.

Diante do exposto, pela Justiça Restaurativa, afasta-se o conceito de somente se determinar a culpa e a pena ao infrator. $\bigcirc$ importante é que ele compreenda o que fez, o que causou com sua ação/omissão e se comprometa a não reincidir. E por sua própria opinião em não consentir seu ato infracional, poderá não reincidir de livre e espontânea vontade, e não somente por ser proibido legalmente e poder ter como resultado uma sanção penal (ROCHA, 20|4). Dessa forma, esse modelo de Justiça consiste numa resposta mais humana na solução dos conflitos penais.

\section{APLICABILIDADE DA JUSTIÇA RESTAURATIVA AO DEPENDENTE QUÍMICO PELO PODERJUDICIÁRIO DO ESTADO DO TOCANTINS}

Sabe-se que um dos problemas que mais aflige a sociedade atualmente é o acesso à justiça. Necessário se faz, neste momento, explanar sobre a distinção entre acesso à justiça e acesso ao judiciário.

Acesso à justiça consiste em direito fundamental/constitucional, principal garantia dos direitos subjetivos, e em torno dele estão todas as garantias destinadas a promover a efetiva tutela dos direitos fundamentais. Dessa forma, o acesso ao poder judiciário está incluso nele. Porém, devido ao fato de a estrutura jurídica não dar suporte para que toda a população tenha acesso a tal na resolução de seus problemas, não há garantia de que todos os direitos expressos sejam efetivamente postos em prática. 
Considerando que o acesso ao poder judiciário é a garantia constitucional de efetivar o direito de ação perante o poder judiciário, e levando-se em conta que a estrutura jurídica não atende a todos, o acesso ao judiciário se torna falho ou restrito a uma parte da população.

Dessa forma, essas falhas ou restrições impossibilitam o efetivo acesso à justiça, e os motivos são vários, como fatores de ordem econômica, social, cultural e lentidão da justiça. Esses fatores, mesmo isolados, já são suficientes para impossibilitar o contato de uma pessoa com o Poder Judiciário, em maior ou menor proporção. Assim, o direito ao acesso à justiça não garante, efetivamente, o direito de acesso ao poder judiciário.

Portanto, a implementação de sistemas alternativos de administração de conflitos baseados na Justiça Restaurativa se faz necessária. $\bigcirc$ objetivo consiste em tornar as instituições mais acessíveis e eficazes no oferecimento de soluções alternativas aos conflitos, problemas vivenciados por todos, até então não superadas pelo sistema formal de Justiça e pelos governos nas três esferas de atuação (PINHO, online).

Os movimentos em favor da Justiça Restaurativa no Brasil tiveram influência da Resolução do Conselho Econômico e Social das Nações Unidas, Resolução n² 2002, de 2012. Nessa Resolução, foram definidos os princípios básicos para a utilização de programas de Justiça Restaurativa em matéria criminal. Particularmente, reportava-se às ações referentes à justiça restaurativa, de modo que se cumprissem os compromissos assumidos no parágrafo $28^{6}$ da Declaração de Viena.

modelo adotado no Brasil é restritivo; por isso, não é cópia dos modelos estrangeiros. Ademais, há carência de transformações legislativas para a aplicação integral desse tipo de justiça (PINHO, online).

Existem, no País, várias aplicações da Justiça Restaurativa, a exemplo de Belo Horizonte-MG (Projeto Mediar, 2006); Santana-SP (Projeto Experimental Cantaneira de Mediação Penal Interdisciplinar, 2005); Campinas-SP (Justiça e Educação - Novas Perspectivas, 2008); Joinville-SC (Projeto Mediação, 2003); Heliópolis e Guarulhos-SP (Projeto Justiça e Educação em Heliópolis e Guarulhos: Parceria para a Cidadania, 2006); São Caetano do Sul-SP (Justiça, Educação e Comunidade: Parcerias para a Cidadania, 2005); Brasília-DF (Projeto no Juizado Especial Criminal do Núcleo de Bandeirante, 2005); Porto Alegre-RS, (Promovendo Práticas Restaurativas no Sistema de Justiça Brasileiro, 2005) (PRUDENTE, 20 I3).

\footnotetext{
${ }^{6}$ 28. A Conferência Mundial sobre Direitos Humanos manifesta a sua consternação perante as violações massivas de Direitos Humanos, em especial sob a forma de genocídio, "limpeza étnica" e violação sistemática de mulheres em situações de guerra, originando êxodos em massa de refugiados e pessoas deslocadas. Ao condenar veementemente tais práticas abomináveis, reitera o apelo para que os autores de tais crimes sejam punidos e tais práticas imediatamente eliminadas.
} 
Com esses exemplos, conclui-se que a Justiça Restaurativa é compatível com o ordenamento jurídico brasileiro, necessitando apenas que os institutos penais tenham sua interpretação reformulada, respeitando-se os direitos e as garantias fundamentais dos cidadãos.

No estado do Tocantins, há iniciativas, ainda que incipientes, em que se aplicam a Justiça Restaurativa, mas são poucas decisões judiciais que se baseiam nela. A Secretaria de Defesa Social (SEDS), do Governo do Estado do Tocantins, conta com o Conselho Sobre Drogas Municipais, que realiza cursos de Terapia Comunitária, conferências sobre o tema e iniciação das tratativas para a realização da pesquisa situacional sobre o consumo de álcool e outras drogas no Estado. Também foi publicada uma Cartilha da Política Estadual sobre Drogas (SEDS, 20 I 4).

Essas políticas públicas têm como objetivo a prevenção do uso abusivo de drogas e de sua dependência química, assim como o tratamento que tenha como base o respeito aos direitos fundamentais dos cidadãos. Procura-se, assim, retirar os envolvidos do ciclo vicioso de violência, tanto os agentes infratores como seus familiares e a comunidade em que estão inseridos.

Nota-se que, em sua maioria, o trabalho de Justiça Restaurativa é feito com dependentes químicos inseridos em contextos de violência. Um exemplo significativo é o da Fazenda da Esperança, comunidade terapêutica com mais de 30 anos de experiência na recuperação de jovens dependentes químicos.

A dependência química encontra-se classificada entre os transtornos psiquiátricos e é considerada uma doença crônica que pode ser tratada e controlada simultaneamente como doença e como problema social (OMS, 2002). Por ser crônica, há progressiva mudança de comportamento do indivíduo, fazendo-o se adaptar à doença com a finalidade de proteger o uso da droga. Além de ser progressiva, considera-se incurável, porém tratável. É uma doença de evolução própria, que pode levar à insanidade, prisão, morte ou ao tratamento. Os danos físicos e sociais, quando percebidos, impulsionam, ainda mais, o dependente químico a uma insaciável busca pelos efeitos da droga (SILVA, 2000). Isso o leva, muitas vezes, a cometer infrações penais.

$\bigcirc$ projeto da Fazenda Esperança, preocupado com o aumento de dependentes químicos e com as consequências dessa dependência, até mesmo no campo penal, foi avaliado como a maior obra da América Latina, que desenvolve tratamento terapêutico e ajuda milhares de famílias. Atualmente, I 5 países, do ocidente ao oriente, executam esse projeto. Seu trabalho se baseia no tripé: convivência em família, trabalho como processo pedagógico e espiritualidade para encontrar um sentido de vida (FAZENDA DAESPERANÇA, online).

Existem outras comunidades terapêuticas no estado do Tocantins, como a Comunidade Terapêutica Rhema, Fênix, Movimento Amor-Exigente, que também tratam de dependentes químicos.

No entanto, sem políticas públicas efetivas que integrem o Poder judiciário, por meio de suas decisões; e o Poder Executivo, por meio de suas ações, o Estado não 
conseguirá enfrentar a luta contra a violência e o uso de drogas. Assim, os programas precisam estar voltados às medidas socioeducativas e protetivas, que dependem também da atividade judiciária para que sejam cumpridas. Isso porque o uso de drogas é um dos motivos que levam os indivíduos a delinquir, o que, mais uma vez, justifica a ação judiciária.

\section{CONCLUSÃO}

A sociedade encontra-se num momento de apreensão em relação à violência associada ao consumo abusivo de drogas, o que leva à dependência química. Observase, nesse quadro, que a Justiça não tem conseguido resolver de forma satisfatória os problemas que relacionam a criminalidade e as drogas. Isso porque o sistema penal brasileiro, em sua maioria, pauta-se pela Justiça Retributiva.

Quando o Estado aplica sanções somente baseadas na Justiça Retributiva aos infratores penais, pouco resultado tem obtido e, como consequência, há alto índice de reincidência criminal. Nessa relação, estão presentes somente o infrator e a vítima, esta relegada a segundo plano na resolução dos conflitos.

Assim, surge, como possibilidade de se alcançarem resultados mais positivos tanto para o infrator quanto para a vítima e a comunidade, a Justiça Restaurativa. Por meio desta, buscam-se resolver os conflitos, assumir responsabilidades e reparar o dano; ao contrário daquela, que visa somente provar delitos, estabelecer culpas e aplicar castigos.

No Brasil, apesar de haver exemplos em que estejam sendo aplicados projetos voltados para a prevenção do uso de drogas e, consequentemente, para a diminuição de violência, reinserção social e tratamento de dependentes químicos, ainda há muito por fazer. Principalmente, necessita-se de políticas públicas que se voltem para o problema da drogadição e seu tratamento.

No Tocantins, poucas são as ações do Estado que promovem a Justiça Restaurativa. Isso porque não há integração entre o Poder Judiciário e o Poder Executivo para que haja políticas públicas destinadas ao cumprimento de sanções atribuídas aos infratores penais, principalmente aos infratores dependentes químicos.

Dessa forma, enquanto não houver objetivos comuns do judiciário e do executivo voltados à prevenção de crimes e uso de drogas e tratamento de dependentes químicos, dificilmente se conseguirá aplicar a Justiça Restaurativa e alcançar a paz social. 


\section{REFERÊNCIAS}

AMANCIO, Mila Loureiro de Castro. Justiça restaurativa: um novo modelo de Justiça. 201 I . Disponível em: < http://jus.com.br/artigos/I 9579/justica-restaurativa-um-novomodelo-de-justica\#ixzz3dpofrbpx>. Acesso em 9 jun. 2015.

BACELLAR, Roberto Portugal; NETO, Joaquim Domingos de Almeida. O modelo restaurativo para a solução adequada de conflitos, no contexto dos juizados especiais criminais e das varas de infância e juventude. In: Integração de competências no desempenho da atividade judiciária com usuários e dependentes de drogas. Coordenação geral de Arthur Guerra de Andrade. Brasília: Ministério da Justiça, Secretaria Nacional de Políticas sobre Drogas, 2011 .

BITENCOURT, Cezar Roberto. Tratado de direito penal: parte geral. v. I. 9. ed. São Paulo: Saraiva, 2004.

BRASIL. Constituição da República Federativa do Brasil de 1988. Disponível em: <http://www.planalto.gov.br/ccivil_03/constituicao/constituicao.htm>. Acesso em 10 jun. 2015.

. Lei n. I.343 de 23 de agosto de 2006. Institui o Sistema Nacional de Políticas Públicas sobre Drogas - Sisnad; prescreve medidas para prevenção do uso indevido, atenção e reinserção social de usuários e dependentes de drogas; estabelece normas para repressão à produção não autorizada e ao tráfico ilícito de drogas; define crimes e dá outras providências. Disponível e m : <http://www.planalto.gov.br/ccivil_03/_ato2004-2006/2006/lei/l I 343.htm>. Acesso em 9 jun. 2015.

. Lei n. 7.210 de II de julho de 1984. Institui a Lei de Execução Penal. Disponível em: <http://www.planalto.gov.br/CCIVIL_03/leis/L7210.htm>. Acesso em 9 jun. 2015.

. Resolução 2002/I 2 da ONU de 24 de julho de 2002. Princípios básicos para utilização de programas de justiça restaurativa em matéria crimina. Disponível em: $<$ http://www.justica2 I .org.br/j2 I .php?id=366\&pg=0\#.VZHboPIViko > . Acesso em 9 jun. 2015.

CARTA DE ARAÇATUBA. Princípios de justiça restaurativa. Carta elaborada pelos integrantes do I Simpósio Brasileiro de Justiça Restaurativa. 28/30 de abril de 2005, na Cidade de Araçatuba/São Paulo. Disponível em: < http://jij.tjrs.jus.br/justicarestaurativa/carta-aracatuba $>$. Acesso em 7 jun. 2015. 
CARTA DE BRASÍLIA. Documento ratificado pelos painelistas e participantes da Conferência Internacional "Acesso à Justiça por Meios Alternativos de Resolução de Conflitos", realizada na cidade de Brasília, Distrito Federal, nos dias 14, I5, 16 e 17 de junho de 2005, com base na carta produzida, em abril do corrente ano, no I Simpósio Brasileiro de Justiça Restaurativa, realizado em Araçatuba - SP, em abril de 2005. Disponível em: <http://ow.ly/KNICZ>. Acesso em 9 jun. 2015.

CARTA DE RECIFE. A Carta de Recife foi elaborada por integrantes e aprovada pelos participantes do II Simpósio Brasileiro de Justiça Restaurativa, realizado na Cidade do Recife, Estado de Pernambuco - Brasil, nos dias 10, I I e I 2 de abril de 2006. Disponível em: <http://www.justica2 I .org.br/j2I .php?id=225\&pg=0\#.VZHWIflViko>. Acesso em 9 jun. 2015.

CARTA DE SÃO LUÍS. Carta elaborada pelos integrantes do I Seminário Brasileiro de Justiça Juvenil Restaurativa, que aconteceu de 07 a 09 de julho de 20 I0, em São Luís, capital do estado do Maranhão. Disponível em: $<$ http://portal.andes.org.br/imprensa/noticias/imp-ult-732896191.pdf>. Acesso em 9 jun. 2015.

DECLARAÇÃO DE VIENA. Declaração e programa de ação de Viena: Conferência Mundial sobre Direitos Humanos. Potal do Direito Internacional. Disponível em: <http://www.oas.org/dil/port/I 993\%20Declara\%C3\%A7\%C3\%A30\%20e\%20Pro grama\%20de\%20Ac\%C3\%A7\%C3\%A3o\%20adoptado\%20pela\%20Confer\%C3 \%AAncia\%20Mundial\%20de\%20Viena\%20sobre\%20Direitos\%20Humanos\%20e m\%20junho\%20de\%201993.pdf> . Acesso em 9 jun. 2015.

FAZENDA DA ESPERANÇA. Projeto da Fazenda Esperança. Disponível em: $<$ http://www.fazenda.org.br/institucional/quem_somos.php>. Acesso em: 9 jun. 2015.

GOMES PINTO, Renato Sócrates. Justiça restaurativa: é possível no Brasil? In: SLAKMON, C.; DE VITTO, R.; GOMES PINTO, R. (Org.). Justiça restaurativa. Brasília: Ministério da Justiça/Programa das Nações Unidas para o Desenvolvimento Pn ud, $\quad 2005$. Disponível e m : <http://www.mj.gov.br/reforma/pdf/publicacoes/Livro\%20Justi\%E7a\%20restaurativ a.pdf $>$. Acesso em 7 jun. 2015.

NEVES, Carlos Eduardo. Justiça retributiva e justiça restaurativa. 2010. Disponível em: <http://www.direitonet.com.br/artigos/exibir/68 I 8/Justica-retributiva-e-justicarestaurativa $>$. Acesso em: 7jun. 2015. 
NUCCl, Guilherme de Souza. Manual de Direito Penal. II. ed. São Paulo: Método/Forense, 2015.

OMS. Organização Mundial da Saúde. Relatório Mundial da Saúde. Saúde mental: nova concepção, nova esperança. I . ed. Brasília: Ministério da Saúde, 2002.

ONU. Organização das Nações Unidas. Handbook on restorative justice programmes. Nova York: United Nations, 2006.

OXHORN, Philip; SLAKMON, Catherine. Micro-justiça, Desigualdade e Cidadania Democrática: A Construção da Sociedade Civil através da Justiça Restaurativa no Brasil. In: SLAKMON, Catherine; DE VITTO, Renato Campos Pinto; PINTO, Renato Sócrates Gomes (Org.). Justiça Restaurativa. Brasília - DF: Ministério da Justiça e Programa das Nações Unidas para o Desenvolvimento - PNUD, 2005.

PENIDO, Egberto de Almeida; MELO, Eduardo Resende. Justiça Restaurativa - um breve esboço. Informativo Interação Magistratura. São Paulo: Escola Paulista da Magistratura, 2005.

PINHO, Rafael Gonçalves de. Justiça Restaurativa: um novo conceito. Disponível em: <http://www.arcos.org.br/periodicos/revista-eletronica-de-direitoprocessual/volume-iii/justiça-restaurativa-um-novo-conceito/\#topo $>$. Acesso em 9 jun. 2015.

PINTO, Renato Sócrates Gomes. Justiça Restaurativa é Possível no Brasil? In: SLAKMON, Catherine; DE VITTO, Renato Campos Pinto; PINTO, Renato Sócrates Gomes (Org.). Justiça Restaurativa. Brasília - DF: Ministério da Justiça e Programa das Nações Unidas para o Desenvolvimento - PNUD, 2005.

PRUDENTE, Neemias Moretti. Algumas reflexões sobre a justiça restaurativa. 20 I 3. Disponível em: <http://www.justiciarestaurativa.org/news/algumas-reflexoes-sobrea-justicarestaurativa $>$. Acesso em 17 jun. 2015.

ROCHA, Giulia Gabriela Ribeiro. Justiça restaurativa: uma alternativa para o sistema penal brasileiro. JusBrasil. 20l4. Disponível em: <http://giuliarocha.jusbrasil.com.br/artigos/I | 4570086/justica-restaurativa-umaalternativa-para-o-sistema-penal-brasileiro>. Acesso em 9 jun. 2015.

SANTOS, Robson Fernando. Justiça restaurativa: um modelo de solução penal mais humano. Mestrado em direito. Florianópolis/SC: Universidade Federal de Santa Catarina, 201 I. 
SEDS. Secretaria de Defesa Social do Estado do Tocantins. Governo e comunidades terapêuticas apresentam trabalhos ao Secretário Nacional de Políticas sobre D rog a s. $\quad 20 \mid 4$ < http://defesasocial to gov br/noticia/2014/3/26/governo-e-comunidadesterapeuticas-apresentam-trabalhos-ao-secretario-nacional-de-politicas-sobredrogas/>. Acesso em 9 jun. 2015.

SILVA, IIma Ribeiro. Alcoolismo e Abuso de Substancias Psicoativas: Tratamento, prevenção e educação. São Paulo: Vetor, 2000.

Recebido em: 21/1 1/2016

Aprovado em: 18/12/2016 
